\title{
Gecko proteins induce the apoptosis of bladder cancer 5637 cells by inhibiting Akt and activating the intrinsic caspase cascade
}

\author{
Geun-Young Kim ${ }^{1, \#}$, Soon Yong Park ${ }^{2, \#}$, Ara Jo ${ }^{2}$, Mira Kim² ${ }^{2}$, Sun-Hee Leem ${ }^{2}$, Woo-Jin Jun ${ }^{3}$, Sang In Shim ${ }^{4}$, \\ Sang Chul Lee ${ }^{5}$ Jin Woong Chung, ${ }^{2, *}$ \\ ${ }^{1}$ Division of Cardiovascular and Rare Disease, Center for Biomedical Sciences, Korea National Institute of Health, Cheongju 28165, \\ ${ }^{2}$ Department of Biological Science, Dong-A University, Busan 47315, ${ }^{3}$ Department of Food and Nutrition, Chonnam National University, \\ Gwangju 61186, ${ }^{4}$ Department of Agronomy, Gyeongsang National University, Jinju 52828, ${ }^{5}$ Research Center for Integrative Cellulomics, \\ Korea Research Institute of Bioscience and Biotechnology, Daejeon 34141, Korea
}

Gecko proteins have long been used as anti-tumor agents in oriental medicine, without any scientific background. Although anti-tumor effects of Gecko proteins on several cancers were recently reported, their effect on bladder cancer has not been investigated. Thus, we explored the anti-tumor effect of Gecko proteins and its cellular mechanisms in human bladder cancer 5637 cells. Gecko proteins significantly reduced the viability of 5637 cells without any cytotoxic effect on normal cells. These proteins increased the Annexin- $\mathrm{V}$ staining and the amount of condensed chromatin, demonstrating that the Gecko proteinsinduced cell death was caused by apoptosis. Gecko proteins suppressed Akt activation, and the overexpression of constitutively active form of myristoylated Akt prevented Gecko proteins-induced death of 5637 cells. Furthermore, Gecko proteins activated caspase 9 and caspase 3/7. Taken together, our data demonstrated that Gecko proteins suppressed the Akt pathway and activated the intrinsic caspase pathway, leading to the apoptosis of bladder cancer cells. [BMB Reports 2015; 48(9): 531-536]

\section{INTRODUCTION}

Bladder cancer, which arises from the epithelial lining of the urinary bladder, is one of the common cancers affecting both men and women. Amongst all cancers, it is the most expensive diagnosis in a patient's lifetime, and accounts for ap-

*Corresponding author. Tel: +82-51-200-7270; Fax: +82-51-200-7269; E-mail: jwchung@dau.ac.kr

${ }^{\text {"}}$ These authors equally contributed to this work.

http://dx.doi.org/10.5483/BMBRep.2015.48.9.117

Received 17 June 2015, Revised 30 June 2015, Accepted 3 August 2015

Keywords: Akt, Apoptosis, Bladder cancer, Caspase, Gecko proteins proximately $3 \%$ of all cancer-related deaths (1). Although the 5 -year survival rates for prostate and kidney cancers have significantly improved in the last three decades, little progress in bladder cancer has been made during this period (2).

Transurethral resection (TUR) is an effective treatment for non-muscle invasive bladder cancer (NMIBC), but is insufficient for treating muscle invasive cancers (3). For muscle invasive bladder cancer, radical cystectomy is the standard treatment, which usually includes the removal of ovaries, uterus and parts of the vagina in females, and the prostate in males. Although combination therapy using radiation and chemotherapy can be used to treat the invasive disease, its effectiveness has not yet been determined. Until recently, Bacillus Calmette-Guerin (BCG) remains the most effective agent for curing NMIBC (4). However, it is ineffective in $30-40 \%$ of NMIBC patients, and also $35 \%$ of the initial responders relapse within 5 years (5). Thus, new treatment options are required for the efficient treatment of bladder cancer.

In oriental medicine, Gecko, a genus of lizards, has been traditionally used in the treatment of inflammatory diseases, including asthma and tuberculosis, although its mechanism of action was not scientifically defined $(6,7)$. It has been revealed that the Gecko protein extract (GPE) is an effective agent against tumors in the digestive system, such as esophageal carcinoma and hepatocarcinoma (7-9). Anti-tumor effects of GPE were mediated by direct induction of apoptosis or reduced angiogenesis in both the in vivo and in vitro models $(7,9,10)$. Recently, we found that the GPE also exhibited its anti-tumor effects on non-digestive cervical cancer (11). However, to date, no studies have reported on the anti-tumor effect of GPE in bladder cancer.

Thus, we undertook to investigate the anti-tumor effect of GPE on bladder cancer, using bladder cancer cell line 5637. Our studies revealed that GPE showed selective cytotoxic activity against 5637 cells, while it did not affect the viability of normal cells. In addition, we found that GPE induced apoptotic cell death of 5637 cells. In effect, GPE induced the activa-

ISSN: 1976-670X (electronic edition)

Copyright (C) 2015 by the The Korean Society for Biochemistry and Molecular Biology

c) This is an open-access article distributed under the terms of the Creative Commons Attribution Non-Commercial License (http://creativecommons.org/licenses/by-nc/4.0) which permits unrestricted non-commercial use, distribution, and reproduction in any medium, provided the original work is properly cited. 
tion of caspase 9 and caspase 3, leading to apoptotic death of bladder cancer cells. Furthermore, GPE suppressed Akt activation, and the overexpression of constantly active form of myristoylated Akt, prevented GPE-induced cell death of 5637 cell. These results suggest that suppression of Akt and activation of caspase 9-caspase 3 cascade are the critical mechanisms of anti-tumor effect of GPE on bladder cancer cells. In addition, the fact that GPE did not show any cytotoxic effect on normal cells suggests that GPE can be a safe and efficient medical treatment for bladder cancer therapy.

\section{RESULTS}

GPE induces the cell death of 5637 cells

To study whether GPE has a cytotoxic effect on bladder cancer cells, we treated 5637 cells with an increasing dose of GPE, BSA or heat-inactivated GPE. After $48 \mathrm{~h}$ incubation, the number of viable cells was counted. As shown in Fig. 1A, GPE decreased the number of viable cells in a dose-dependent manner, whereas BSA or heat-inactivated GPE did not affect the number of viable cells. Interestingly, GPE did not affect the viability of normal cells such as mouse myoblast cells (C2C12), mouse embryonic fibroblasts (MEF), human skin fibroblasts (HS27), and human foreskin fibroblasts (Nuff) (Fig. 1B). MTT assay (Fig. 1C) and microscopic observation (data not shown) also showed that GPE reduced the number of viable cells. GPE showed the best cytotoxic effect at a concentration of 500 $\mu \mathrm{g} / \mathrm{ml}$ in all assays; we therefore treated the 5637 cell with $500 \mu \mathrm{g} / \mathrm{ml}$ of GPE and counted the viable cells daily. This ap- plication of GPE dramatically suppressed the number of viable cells, as shown in Fig. 1D, demonstrating the cytotoxic effect of GPE on 5637 cells.

\section{GPE induces the apoptosis of 5637 cell}

To examine whether GPE-induced cell death was caused by apoptosis, we measured the translocation of phosphatidylserine to the outer membrane, using Annexin- $\mathrm{V}$ staining. As shown in Fig. 2A, GPE treatment increased the staining of Annexin- $\mathrm{V}$ in a dose dependent manner, proving that GPE induced the apoptotic cell death of 5637 cells. We further analyzed the apoptotic cell death by staining the condensed chromatin with anti-single strand DNA (ApoStain) (12). As shown in Fig. 2B, treated cells showed an increased amount of condensed chromatins, thus confirming apoptotic cell death by GPE.

\section{Suppression of Akt mediates GPE-induced 5637 cell death} Akt is the typical survival factor in various cancer cells, including bladder cancer (13-15), and Akt suppression was critical for exhibiting the anti-tumor effect of various bioactive peptides $(14,16)$. In addition, we had previously shown GPE induced cervical cancer cell death by inhibiting the Akt pathway (11). Thus, we examined the involvement of Akt pathway in GPE-induced apoptosis of 5637 cell. Cells were treated with GPE in a dose-dependent manner, and the levels of phosphorylated Akt were evaluated by immunoblotting (17). We found that Akt was phosphorylated at the basal level, and in consistence with our previous observations in cervical cancer
A
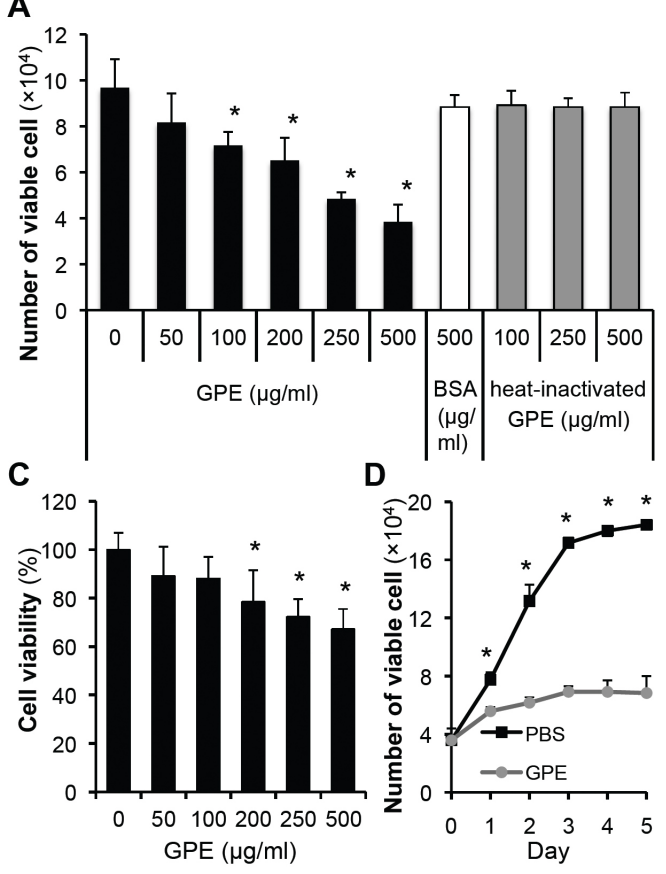

B

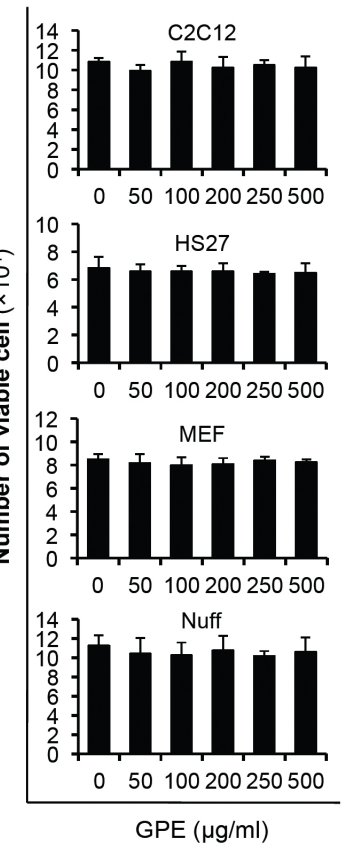

Fig. 1. GPE induces the cell death of 5637 cells. (A) 5637 cells were seeded in 24-well cell culture plates, at a density of $2 \times 10^{4}$ cells/well. Next day, cells were treated with indicated concentrations of GPE, BSA or heat-inactivated GPE, and further incubated for $48 \mathrm{~h}$. Cells were then trypsinized, and the number of viable cells was counted. $* \mathrm{P}<0.05$, compared with no GPE treatment. (B) Cells were seeded in 24-well cell culture plates at a density of $2 \times 10^{4}$ cells/well. Next day, cells were treated with indicated concentrations of GPE and further incubated for $48 \mathrm{~h}$. Cells were trypsinized and the number of viable cells counted. (C) 5637 cells were treated with indicated concentrations of GPE for $48 \mathrm{~h}$ and the MTT assay was performed, as described in Materials and Methods. ${ }^{*} \mathrm{P}<0.05$, compared with no GPE treatment. (D) The number of viable 5637 cells treated with control buffer (PBS) or GPE $(500 \mu \mathrm{g} / \mathrm{ml})$ were counted daily. ${ }^{*} \mathrm{P}<0.05$, compared with respective day control. 
A

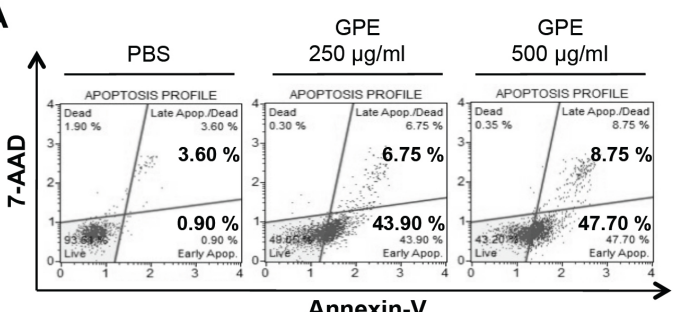

B
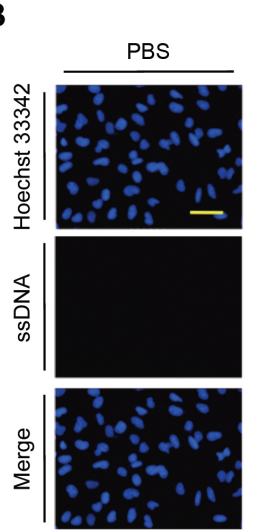
GPE
$\mathrm{GPE}$
$250 \mu \mathrm{g} / \mathrm{ml}$
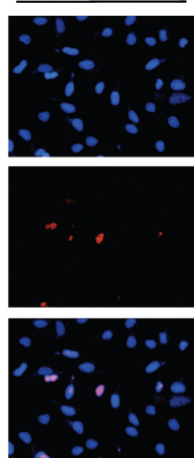
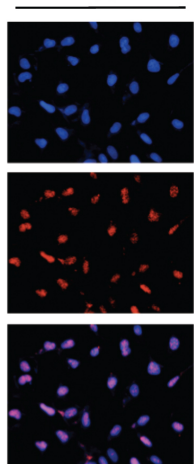

Fig. 2. GPE induces the apoptosis of 5637 cells. (A) 5637 cells were treated with control buffer (PBS), $250 \mu \mathrm{g} / \mathrm{ml}$ or $500 \mu \mathrm{g} / \mathrm{ml}$ GPE for $48 \mathrm{~h}$, Annexin-V staining was performed using a Muse ${ }^{\mathrm{TM}}$ Annexin V \& Dead cell kit, as described in Materials and Methods. (B) 5637 cells were treated with control buffer (PBS), $250 \mu \mathrm{g} / \mathrm{ml}$ or $500 \mu \mathrm{g} / \mathrm{ml}$ GPE for $48 \mathrm{~h}$, the amount of condensed chromatin was analyzed by ApoStaining, as described in Materials and Methods. Bar, $100 \mu \mathrm{m}$.

cells (11), GPE suppressed the Akt phosphorylation (Fig. 3A, B). To show that suppression of Akt is critical for the GPE-induced cell death, we treated 5637 cells with either GPE, Wortmannin, or in combination, incubated cells for $48 \mathrm{~h}$, and counted the number of viable cells. Interestingly, $100 \mathrm{nM}$ Wortmannin showed a comparable cytotoxic effect as 500 $\mu \mathrm{g} / \mathrm{ml} \mathrm{GPE}$, against the 5637 cells, co-treatment of these reagents further decreased the number of viable cells (Fig. 3C), implying that the Akt pathway is involved in GPE-induced death of 5637 cell. Furthermore, transfection of the constitutively active form of myristoylated Akt rescued the GPE-induced cell death (Fig. 3D). These results suggest that GPE induces 5637 cell death by inhibiting the Akt pathway.

\section{Activation of intrinsic caspase cascade by GPE}

Since Akt has been suggested to inhibit the activation of caspase 9 (18-20), we investigated the involvement of intrinsic caspase cascade activation in GPE-induced apoptosis. Pretreatment with pan-caspase inhibitor (Z-VAD-FMK) suppressed the GPE-induced cell death (Fig. 4A), suggesting the involvement of caspase activation in cell death induced by GPE. Next, we measured the activation of effector caspases, such as caspase 3/7. As shown in Fig. 4B, GPE induced the activation of caspase $3 / 7$, with a simultaneous increase of apoptotic cell death. Caspase 9 is an initiator caspase which leads to cleavage (activation) of caspase 3/7 (21) and blockade of Akt activated caspase 9 (18-20). Thus, we hypothesized that caspase 9 would be cleaved by GPE. Indeed, GPE induced the cleavage of caspase 9 as well as caspase 3 (Fig. 4C, D), suggesting the GPE activated caspase 9-caspase $3 / 7$ cascade leads to the apoptotic cell death of 5637 cell.
A

GPE $0 \quad 50 \quad 100200250500(\mu \mathrm{g} / \mathrm{ml})$

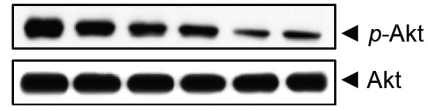

C

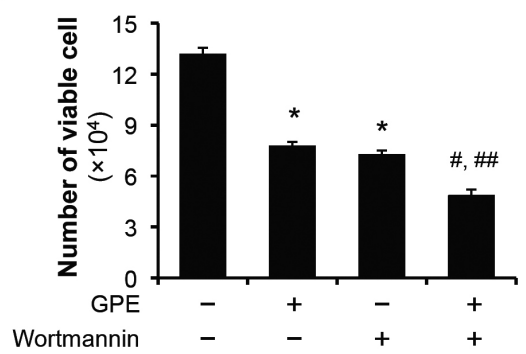

B

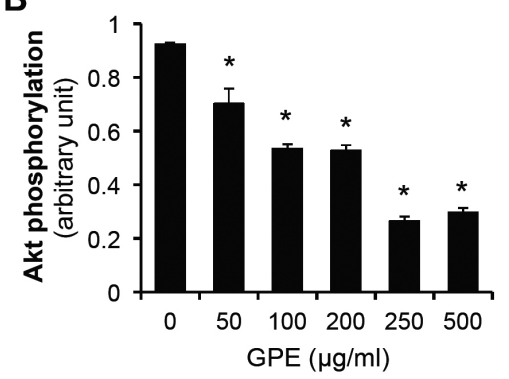

D

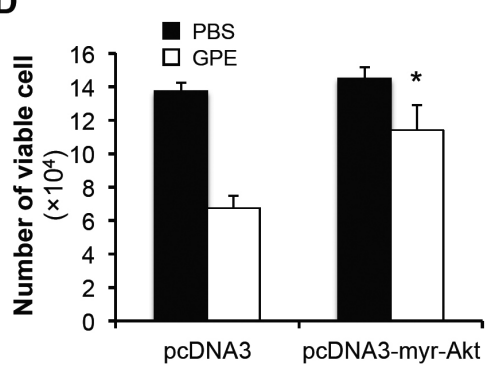

Fig. 3. GPE induces the 5637 cell death by suppressing Akt phosphorylation. (A) 5637 cells were treated with indicated concentrations of GPE for $48 \mathrm{~h}$, the phosphorylation of Akt at Ser 473 was analyzed by immunoblotting. (B) Quantification of Akt phopshorylation that was normalized to the expression of total Akt. $* \mathrm{P}<0.05$, compared with no GPE treatment. (C) 5637 cells were seeded in 24-well cell culture plates at the density of $2 \times 10^{4}$ cells/well. Next day, cells were treated with $500 \mu \mathrm{g} / \mathrm{ml} \mathrm{GPE}$, with the pretreatment of Wortmannin (100 nM) for $2 \mathrm{~h}$, where necessary. After 48 $\mathrm{h}$ incubation, cells were trypsinized and the number of viable cells was counted. $* \mathrm{P}<0.05$, compared with no treatment. ${ }^{\#} \mathrm{P}<0.05$, compared with GPE treatment. ${ }^{\#} \mathrm{P}<0.05$, compared with Wortmannin treatment. (D) 5637 cells transfected with pcDNA3 or pcDNA3-myr-Akt, were incubated with $500 \mu \mathrm{g} / \mathrm{ml}$ GPE for $48 \mathrm{~h}$, and viable cells were counted. *P $<0.05$, compared with pcDNA3 treated with GPE. 
A

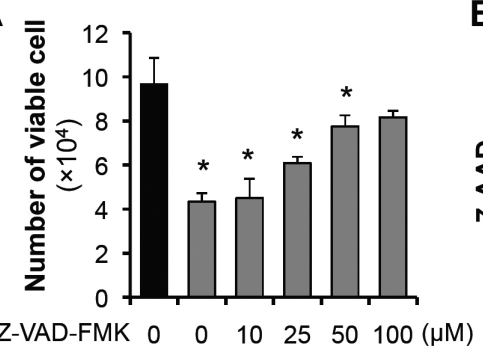

GPE $0500500500500500(\mu \mathrm{g} / \mathrm{ml})$

C

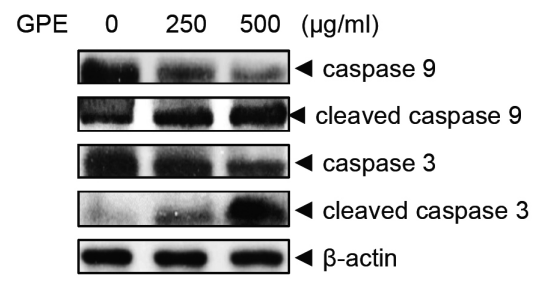

B

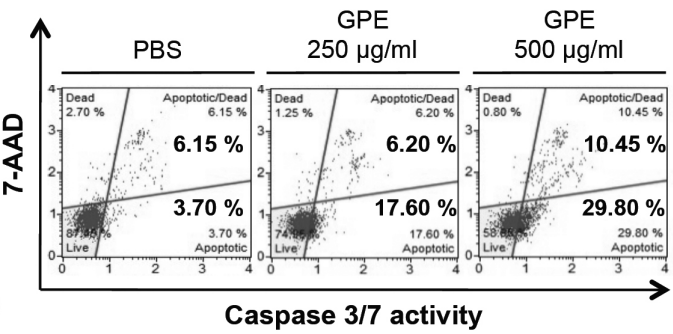

D

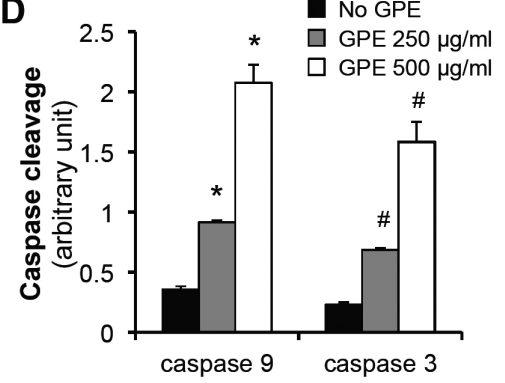

Fig. 4. Intrinsic caspase cascade is activated by GPE. (A) 5637 cells were seeded in 24-well cell culture plates, at a density of $2 \times 10^{4}$ cells/well. Next day, cells were treated with $500 \mu \mathrm{g} / \mathrm{ml}$ GPE, after a pretreatment with Z-VADFMK (indicated concentration) for $3 \mathrm{~h}$. After $48 \mathrm{~h}$ incubation, cells were trypsinized and the number of viable cells was counted. ${ }^{*} \mathrm{P}<0.05$, compared with no treatment. (B) 5637 cells were treated with control buffer (PBS), 250 $\mu \mathrm{g} / \mathrm{ml}$ or $500 \mu \mathrm{g} / \mathrm{ml}$ GPE for $48 \mathrm{~h}$, caspase $3 / 7$ activity was analyzed using a Muse $^{\mathrm{TM}}$ Caspase-3/7 kit, as described in Materials and Methods. (C) 5637 cells were treated with $250 \mu \mathrm{g} / \mathrm{ml}$ or 500 $\mu \mathrm{g} / \mathrm{ml}$ GPE for $48 \mathrm{~h}$, the cleavages of capase 9 and caspase 3 were analyzed by immunoblotting. (D) Quantification of cleaved caspase 9 and cleaved caspase 3 that was normalized to the expression of $\beta$-actin. ${ }^{*} P<0.05$, compared with caspase 9 with no GPE treatment. ${ }^{\#} \mathrm{P}<0.05$, compared with caspase 3 with no GPE treatment.

\section{DISCUSSION}

The major finding of this study was that GPE suppressed the Akt pathway and activated the intrinsic caspase pathway, leading to apoptosis of bladder cancer cells. Specifically, we showed that the overexpression of constitutively active form of myristoylated Akt decreased the GPE-induced death of 5637 cells, suggesting the critical step of Akt inactivation is involved in imposing the anti-tumor effect of GPE on bladder cancer. In addition, GPE also exerted a comparable cytotoxicity against EJ cells, another typical bladder cancer cell line (Supplementary Fig. 1), suggesting the universal anti-tumor activity of GPE against bladder cancer cells. Furthermore, we showed that GPE activated initiator caspase, (caspase 9) and effector caspases, (caspase 3/7) to bring about the apoptosis of bladder cancer cells. On the basis of our results, we propose a model for the anti-tumor effect of GPE in bladder cancer cells (Supplementary Fig. 2).

GPE has been used as an oriental medicine for its anticancer properties against tumors. Recently, some of its apoptosis-inducing mechanisms in cancers of the digestive system have been reported. For example, aqueous GPE inhibited the proliferation of human hepatocarcinoma cell BEL-7402 by inducing cell differentiation via an ERK1/2 activation (8). Alcoholic GPE induced the apoptosis of human esophageal squamous carcinoma cell line EC9706 by increasing the expression of Bax (22). Furthermore, alcoholic GPE induced the apoptosis of human esophageal squamous carcinoma cell line EC109 by increasing the expression of Fas and caspase-3 (23). However, the anti-tumor effect of GPE on bladder cancer cells has not yet been investigated. Thus, the present study is the first to show the suppression of Akt, and the activation of intrinsic caspase pathway, for the induction of bladder cancer apoptosis by GPE. We had recently reported that GPE had a cytotoxic effect on non-digestive cervical cancers, the mechanism involved being the suppression of Akt (11). Thus, we postulate that Akt suppression is the critical determinant for the apoptosis of GPE-treated non-digestive cancer cells, such as cervical cancer and bladder cancer.

In the present study, we proved that the native Gecko extracts showed anti-tumor activity against the bladder cancer cells, however, when heat-inactivated, they did not affect the viability of these cancer cells (Fig. 1A). The fact that the heatinactivated extracts lost their cytotoxic activity may suggest that the protein from Gecko extract is critical for exhibiting the anti-tumor effect against the bladder cancers. To investigate the proteins that compose the Gecko extract, we had previously performed 2-dimensional electrophoresis and categorized the identified proteins by mass spectrometry (11). Among the proteins categorized, $41 \%$ were metabolism-related proteins and $23 \%$ were tryptase inhibitors (11). Presently, it is not known as to which proteins in the Gecko extract exert their anti-tumor activity on bladder cancer cells. However, based on our observations (suppression of Akt pathway by GPE), we think tryptase inhibitors can be good candidates for the anti-tumor activity of GPE, since tryptase has been suggested to activate the Akt pathway $(24,25)$. Further analysis for the identification of the functional protein(s), that induce the apoptosis of bladder cancer cells, will be required.

Importantly, we observed that the viability of normal cells was not affected by GPE (Fig. 1B), suggesting that the effect of GPE on apoptosis was specific to cancer cells $(8,11,22,23)$. 
Considering the critical role of Akt pathway in the progression of bladder cancer $(14,15,26)$, with no corresponding cytotoxic effect on normal cells, our findings suggest that GPE can be a promising therapeutic candidate for the development of an anti-cancer drug for bladder cancer.

\section{MATERIALS AND METHODS}

\section{Cell culture, antibodies, and reagents}

Bladder cancer 5637 cells and EJ cells were grown in RPMI 1640 medium (Invitrogen, Carlsbad, CA) supplemented with 10\% fetal bovine serum (FBS, Hyclone, Logan, UT) and penicillin/streptomycin $(100 \mathrm{U} / \mathrm{ml}$ and $100 \mu \mathrm{g} / \mathrm{ml}$, respectively; HyClone). MEF, C2C12, HS27 and Nuff were grown in high glucose DMEM (Invitrogen) supplemented with 10\% FBS and penicillin/streptomycin $(100 \mathrm{U} / \mathrm{ml}$ and $100 \mu \mathrm{g} / \mathrm{ml}$, respectively). All cells were grown at $37^{\circ} \mathrm{C}$ in a humidified incubator with $5 \% \mathrm{CO}_{2}$. Antibodies against Akt, p-Akt (Ser473), caspase-3 and caspase-9 were from Enzo Life Sciences (Farmingdale, NY); antibody against $\beta$-actin from Bethyl Laboratories Inc (Montgomery, TX). Specific inhibitors of PI3-kinase/Akt (Wortmannin) and pan-caspase inhibitor (Z-VAD-FMK) were purchased from Sigma (St. Louis, MO).

\section{Animal housing and use}

Young (4-6 weeks) Eublepharis macularius were obtained from a commercial supplier (Mowglipet, Seoul, Korea), and bred in captivity. Briefly, the Geckos were housed individually in standard mouse-sized polycarbonate enclosures in an isolated room, with an ambient humidity of $40-50 \%$, at a room temperature of $\sim 24^{\circ} \mathrm{C}$. Animals were fed daily a diet of gut-loaded mealworms (larval Tenebrio spp.) dusted with powdered calcium and vitamin D3 (cholecalciferol) supplement.

\section{Extraction of protein from lizard}

Animals of 8 to $11 \mathrm{~cm}$ in length were anaesthetized in $0.02 \%$ to $0.05 \%$ MS-222 (Argent Chemical Laboratories, Redmond, WA), and tails were amputated with a length of $0.5 \mathrm{~cm}$. The amputated tails were rinsed in sterile phosphate buffered saline (PBS) and homogenized using a homogenizer. The homogenates were centrifuged $\left(13,000 \mathrm{rpm}\right.$ for $10 \mathrm{~min}$ at $\left.4^{\circ} \mathrm{C}\right)$ and the supernatants were passed through a $0.45 \mu \mathrm{m}$ syringe filter. The filtrates were dialyzed with MAXI GeBaFlex-tubes, according to the manufacturer's protocol (Gene Bio-Application LTD, Kfar-Hanagid, Israel).

\section{Viable cell number counting}

Cells were seeded in 24-well cell culture plates at a density of $2 \times 10^{4}$ cells/well. Next day, cells were treated with designated concentrations of GPE and further incubated for $48 \mathrm{~h}$. The cells were then trypsinized, and stained using a Trypan blue. Then, the non-stained viable cell numbers were counted using hemacytometer, under an optical microscope. As required by the respective experiment, the cells were incubated with Wortmannin for $2 \mathrm{~h}$ or Z-VAD-FMK for $3 \mathrm{~h}$ prior to treatment with GPE.

\section{MTT assay}

Cells were seeded in 96-well cell culture plates at a density of $5 \times 10^{3}$ cells/well. Next day, the cells were treated with designated concentrations of GPE or standard compounds. After $48 \mathrm{~h}$ incubation, MTT (final $0.5 \mathrm{mg} / \mathrm{ml}$ ) was added to these cells, and further incubated at $37^{\circ} \mathrm{C}$ for $4 \mathrm{~h}$. When the purple precipitate was visible, the medium was removed and dimethylsulfoxide added. After shaking for $10 \mathrm{~min}$ to thoroughly mix the formazan with dimethylsulfoxide, the optical density was determined at $550 \mathrm{~nm}$.

\section{Immunofluorescence staining (ApoStain staining)}

Cells were seeded on gelatin-coated coverslips in 24-well cell culture plates, at a density of $5 \times 10^{4}$ cells/well. Next day, cells were treated with designated concentrations of GPE. After $48 \mathrm{~h}$, cells were fixed with $4 \%$ paraformaldehyde for $5 \mathrm{~min}$, followed by permeabilization with $0.5 \%$ NP-40 for $10 \mathrm{~min}$. The cells were incubated with blocking buffer $(20 \%$ FBS in PBS) for $30 \mathrm{~min}$, followed by anti-single strand DNA antibody (1:100 dilution in $5 \% \mathrm{FBS}$ in PBS) for $1 \mathrm{~h}$ at $37^{\circ} \mathrm{C}$. The cells were washed three times with PBS, and incubated with the fluorescence-conjugated secondary antibody (1:300 dilution, Alexa Fluor 568, Invitrogen) for $1 \mathrm{~h}$ at $37^{\circ} \mathrm{C}$. After staining with Hoechst 33342 (Sigma), cells were analyzed under a fluorescence microscope.

\section{Annexin V Assay and Caspase 3/7 Assay}

5637 cells were incubated with designated concentrations of GPE for $48 \mathrm{~h}$ and the apoptotic percentage of these cells was determined by Muse ${ }^{\mathrm{TM}}$ Annexin $\mathrm{V}$ \& Dead cell kit (Millipore, Billerica, MA), and Muse ${ }^{\mathrm{TM}}$ Caspase-3/7 kit (Millipore), using a Muse $^{\mathrm{TM}}$ Cell analyzer, as per the manufacturers' instructions.

\section{Westem blot analysis}

Cells were seeded in 6-well cell culture plates at a density of 5 $\times 10^{5}$ cells/well. Next day, cells were treated with designated concentrations of GPE and further incubated for $48 \mathrm{~h}$. Cells were lysed in cell lysis buffer $[20 \mathrm{mM}$ Tris-HCl $(\mathrm{pH} 6.8), 150$ $\mathrm{mM} \mathrm{NaCl}, 1$ mM EDTA, 1 mM EGTA, 1\% Triton X-100] supplemented with a protease inhibitor (complete-Mini, Roche, Indianapolis, IN) for $20 \mathrm{~min}$ on ice, and then centrifuged at $13,000 \mathrm{~g}$ for $20 \mathrm{~min}$ at $4^{\circ} \mathrm{C} .20 \mu \mathrm{g}$ of the extracted proteins were separated by sodium dodecyl sulfate (SDS)-polyacrylamide gel electrophoresis (PAGE) and transferred onto polyvinylidene difluoride (PVDF) membranes. The membranes were blocked in $5 \%$ nonfat milk, and incubated sequentially with appropriate primary antibodies and HRP-conjugated secondary antibodies. Immunoreactivity was detected with Enhanced Chemiluminescence (ECL, Thermo Scientific Inc. Rockford, IL) kit on X-ray film. 


\section{Transient transfection}

5637 cells $\left(5 \times 10^{5}\right.$ cells/well) were seeded in the 6 -well cell culture plates and incubated for $16 \mathrm{~h}$. Cells were then transfected with $2 \mu \mathrm{g}$ of constantly active form of myristoylated Akt expression vector (pcDNA3-myr-Akt) or empty vector (pcDNA3), using Maestrofectin ${ }^{\mathrm{TM}}$ transfection reagent (Omicsbio, Taipei City, Taiwan), according to the manufacturer's instructions. After $24 \mathrm{~h}$ incubation in complete media, cells were exposed to the designated concentrations of GPE for $48 \mathrm{~h}$, for further experiments.

\section{Statistical analysis}

All experiments were repeated at least three times. Data are presented as means \pm standard deviation. Analyses were performed with the Student's t test, and values of $\mathrm{P}<0.05$ were considered significant.

\section{ACKNOWLEDGEMENTS}

This work was partially supported by the National Research Foundation of Korea (NRF-2010-0009086, NRF-2003-003C00110, and 2012M3A9C7050184) and the Brain Busan 21 Project.

\section{REFERENCES}

1. Botteman MF, Pashos CL, Redaelli A, Laskin B and Hauser R (2003) The health economics of bladder cancer: a comprehensive review of the published literature. Pharmacoeconomics 21, 1315-1330

2. Kaplan AL, Litwin MS and Chamie K (2014) The future of bladder cancer care in the USA. Nat Rev Urol 11, 59-62

3. Stenzl A, Cowan NC, De Santis M et al (2009) The updated EAU guidelines on muscle-invasive and metastatic bladder cancer. Eur Urol 55, 815-825

4. Herr HW and Morales A (2008) History of bacillus Calmette-Guerin and bladder cancer: an immunotherapy success story. J Urol 179, 53-56

5. Addeo R, Caraglia M, Bellini S et al (2010) Randomized phase III trial on gemcitabine versus mytomicin in recurrent superficial bladder cancer: evaluation of efficacy and tolerance. J Clin Oncol 28, 543-548

6. Connett GJ and Lee BW (1994) Treating childhood asthma in Singapore: when West meets East. BMJ 308, 1282-1284

7. Liu F, Wang JG, Wang SY, Li Y, Wu YP and Xi SM (2008) Antitumor effect and mechanism of Gecko on human esophageal carcinoma cell lines in vitro and xenografted sarcoma 180 in Kunming mice. World J Gastroenterol 14, 3990-3996

8. Wang YX, Gu XX, Geng D et al (2014) Differentiation of bel-7402 human hepatocarcinoma cells induced by aqueous extracts of fresh gecko (AG) and its anti-tumor activity in vivo. J Ethnopharmacol 155, 1583-1588

9. Song Y, Wang JG, Li RF et al (2012) Gecko crude peptides induce apoptosis in human liver carcinoma cells in vitro and exert antitumor activity in a mouse ascites $\mathrm{H} 22$ xenograft model. J Biomed Biotechnol 2012, 743573
10. Zhang SX, Zhu C, Ba Y et al (2012) Gekko-sulfated glycopeptide inhibits tumor angiogenesis by targeting basic fibroblast growth factor. J Biol Chem 287, 13206-13215

11. Jeong AJ, Chung CN, Kim HJ et al (2012) Gecko Proteins Exert Anti-Tumor Effect against Cervical Cancer Cells Via PI3-Kinase/Akt Pathway. Korean J Physiol Pharmacol 16, 361-365

12. Li J, Jiang K, Qiu X et al (2014) Overexpression of CXCR4 is significantly associated with cisplatin-based chemotherapy resistance and can be a prognostic factor in epithelial ovarian cancer. BMB Rep 47, 33-38

13. Altomare DA and Testa JR (2005) Perturbations of the AKT signaling pathway in human cancer. Oncogene 24, 7455-7464

14. Zhao B and Li X (2014) Altholactone induces reactive oxygen species-mediated apoptosis in bladder cancer T24 cells through mitochondrial dysfunction, MAPK-p38 activation and Akt suppression. Oncol Rep 31, 2769-2775

15. Choi EM, Kwak SJ, Kim YM et al (2005) COX-2 inhibits anoikis by activation of the PI-3K/Akt pathway in human bladder cancer cells. Exp Mol Med 37, 199-203

16. Sagar S, Esau L, Holtermann K et al (2013) Induction of apoptosis in cancer cell lines by the Red Sea brine pool bacterial extracts. BMC Complement Altern Med 13, 344

17. Lee HW, Jang KS, Choi HJ, Jo A, Cheong JH and Chun KH (2014) Celastrol inhibits gastric cancer growth by induction of apoptosis and autophagy. BMB Rep 47, 697-702

18. Watanabe T, Nakamura S, Ono T et al (2014) Pyrrolidinium fullerene induces apoptosis by activation of procaspase-9 via suppression of Akt in primary effusion lymphoma. Biochem Biophys Res Commun 451, 93-100

19. Zhou H, Li XM, Meinkoth J and Pittman RN (2000) Akt regulates cell survival and apoptosis at a postmitochondrial level. J Cell Biol 151, 483-494

20. Jeong SJ, Dasgupta A, Jung KJ et al (2008) PI3K/AKT inhibition induces caspase-dependent apoptosis in HTLV-1transformed cells. Virology 370, 264-272

21. Riedl SJ and Shi Y (2004) Molecular mechanisms of caspase regulation during apoptosis. Nat Rev Mol Cell Biol 5, 897-907

22. Wang X, Wang S and Wang J (2010) [Effect of gecko alcohol extract on human esophageal squamous carcinoma cell line EC9706 and anti-tumor activity in vivo]. Zhongguo Zhong Yao Za Zhi 35, 2175-2179

23. Song JY, Wang XL, Wang JG et al (2011) [Inhibitory effects of Gecko alcohol extract on human esophageal squamous carcinoma cell line EC-109 proliferation and associated mechanism]. Zhong Yao Cai 34, 1020-1023

24. Ma Y, Zhang B, Qian R, Lu C, Zhao F and Yin L (2006) Tryptase activates PKB in inflammatory reaction in ECV304 cells. Biochim Biophys Acta 1763, 313-321

25. Brown JK, Hollenberg MD and Jones CA (2006) Tryptase activates phosphatidylinositol 3-kinases proteolytically independently from proteinase-activated receptor- 2 in cultured dog airway smooth muscle cells. Am J Physiol Lung Cell Mol Physiol 290, L259-269

26. Liao AC, Kuo CC, Huang YC et al (2014) Naringenin inhibits migration of bladder cancer cells through downregulation of AKT and MMP2. Mol Med Rep 10, 15311536 